\title{
Dietary intake of schizophrenic patients in Nithsdale, Scotland: case-control study
}

\author{
Robin McCreadie, Elizabeth Macdonald, Claire Blacklock, Deepa Tilak-Singh, David Wiles, \\ Jennifer Halliday, John Paterson
}

Department of Clinical Research, Crichton Royal Hospital, Dumfries DG1 4TG

Robin McCreadie, director

Elizabeth

Macdonald, research fellow

Deepa Tilak-Singh, registrar

Department of Biochemistry, Dumfries and Galloway Royal Infirmary, Dumfries DG1 4AP

Claire Blacklock, research biochemist

David Wiles,

principal biochemist John Paterson, consultant biochemist

Greencroft Medical Centre (North), Greencroft Wynd, Annan DG12 6BG Jennifer Halliday, trainee general practitioner

Correspondence to: Dr McCreadie rgmccreadie_crh@ compuserve.com

BMJ 1998:317:784-5
The move to community care means that most schizophrenic patients now live outside hospital. Patients in the community are supported in various ways-for example, through drugs and nursing support. However, schizophrenic patients die early, especially from cardiovascular disease, which is promoted by an inappropriate diet. ${ }^{1}$ Are schizophrenic patients making faulty dietary choices?

\section{Subjects, methods, and results}

The study took place in Nithsdale, south west Scotland. It focused on schizophrenic patients living in accommodation provided by the Dumfries and Galloway Mental Health Association. Their position in the community had been assessed by social services as sufficiently precarious for them to need additional support. The residents, however, are encouraged to be responsible for their own domestic chores, including shopping and cooking. Each patient was matched with a normal control for sex, age, smoking status (smoker $v$ non-smoker), and employment status-variables that affect a person's diet. All patients were unemployed.

Patients and controls were interviewed by a psychiatrist. The current average weekly food intake was obtained through a modified version of an established food frequency questionnaire. ${ }^{2}$ Also recorded were patients' and controls' height and weight. Patients' mental state was examined using the positive and negative syndrome scale for schizophrenia. A blood sample was taken to measure serum concentrations of cholesterol and vitamin E. ${ }^{3}$

We studied 30 patients (17 men; mean age 44 (SD 15 , range 20-79) years). Twenty three patients smoked. More patients (20) than controls (11) were overweight or obese, as assessed by body mass index (weight (kg)/ (height $\left.(\mathrm{m})^{2}\right)$ ); McNemar's test, $\left.\chi^{2}=4.27 ; \mathrm{P}=0.04\right)$. The patients consumed significantly less energy, total fibre, retinol, carotene, vitamin $\mathrm{C}$, vitamin $\mathrm{E}$, and alcohol (table). In all, $83 \%$ of the patients consumed less fibre, $71 \%$ of the male and $69 \%$ of the female patients consumed less vitamin $\mathrm{E}$, and $70 \%$ of the patients and $73 \%$ of the controls consumed more energy from saturated fats than the suggested UK estimated average requirements (the amounts that any stated group of people will, on average, need). ${ }^{4}$ The patients, when compared with the controls, consumed fewer fruit portions (median weekly intake 2.3 (range 0-20) $v 7.0$ (range 0-33); Wilcoxon matched pairs signed rank test, median difference 3.5 (95\% confidence interval 0.5 to $7.5) ; \mathrm{P}=0.03)$ and vegetable portions (10.0 (1-23) $v$ 19.0 (4-34); 8.5 (4.0 to 12.0$) ; \mathrm{P}=0.001$ ).

Fewer patients than controls ( $8 v 18$; McNemar's test, $\chi^{2}=6.7 ; \mathrm{P}=0.01$ ) had a ratio of serum vitamin $\mathrm{E}$ concentration to cholesterol concentration of over 5 (said to be necessary to protect against cardiovascular disease).

Where dietary measurements in the patients differed significantly from those in the controls, correlations between these measurements and scores in the positive, negative, and total symptom scales were measured. In female patients, a positive correlation was found between positive symptoms and alcohol intake $(\mathrm{rho}=0.75, \mathrm{P}=0.006)$.

\section{Comment}

Most patients smoked and were overweight or obese; their intake of saturated fat was higher than recommended; and antioxidant intake and ratios of serum vitamin E concentration to cholesterol concentration were low. These factors are associated with cardiovascular disease. ${ }^{1}$ Patients on average consumed

Daily median (range) intake of various substances and estimated average requirements

\begin{tabular}{|c|c|c|c|c|c|c|c|c|c|c|}
\hline \multirow[b]{2}{*}{ Intake/day } & \multicolumn{2}{|c|}{ Men } & \multicolumn{2}{|c|}{ Women } & \multicolumn{2}{|c|}{ All } & \multicolumn{2}{|c|}{ Wilcoxon signed ranks test } & \multicolumn{2}{|c|}{$\begin{array}{l}\text { Estimated average } \\
\text { requirements }\end{array}$} \\
\hline & $\begin{array}{c}\text { Patients } \\
(n=17)\end{array}$ & $\begin{array}{c}\text { Controls } \\
(n=17)\end{array}$ & Patients (n=13) & Controls (n=13) & Patients ( $n=30)$ & Controls $(n=30)$ & $\begin{array}{l}\text { Median difference } \\
\quad(95 \% \mathrm{Cl})\end{array}$ & $\mathbf{P}$ & Men & Women \\
\hline Energy (MJ) & $\begin{array}{c}11.84 \\
(7.67-17.93)\end{array}$ & $\begin{array}{c}14.19 \\
(6.94-23.22)\end{array}$ & $8.87(5.07-13.02)$ & $9.99(5.25-16.25)$ & $\begin{array}{c}9.71 \\
(5.07-17.94)\end{array}$ & $\begin{array}{c}11.98 \\
(5.25-23.22)\end{array}$ & $2.06(0.26-4.23)$ & 0.04 & $9.40^{*} \dagger$ & $8.11^{\star} \dagger$ \\
\hline Protein $(\mathrm{g})$ & $\begin{array}{c}92.5 \\
(65.1-157.4)\end{array}$ & $\begin{array}{c}114.2 \\
(74-633)\end{array}$ & $68.7(38.4-104.2)$ & $82.5(40.5-142.2)$ & $\begin{array}{c}84.5 \\
(38.4-157.4)\end{array}$ & $\begin{array}{c}96.0 \\
(40.5-633.0)\end{array}$ & $15.9(-1.1$ to 32.8$)$ & 0.07 & $44.4 \ddagger$ & $36.0 \neq$ \\
\hline Total fibre (g) & $\begin{array}{c}13.0 \\
(8.5-20.8) \\
\end{array}$ & $\begin{array}{c}22.0 \\
(8.7-86.2) \\
\end{array}$ & $10.7(7.3-18.0)$ & $15.5(10.7-22.9)$ & $12.6(7.3-20.8)$ & $18.9(8.7-86.2)$ & 7.0 (3.6 to 10.6$)$ & 0.0001 & $18 \ddagger$ & $18 \ddagger$ \\
\hline Retinol $(\mu \mathrm{g})$ & $\begin{array}{c}647 \\
(294-1498) \\
\end{array}$ & $\begin{array}{c}817 \\
(134-12341) \\
\end{array}$ & $533(288-7556)$ & $817(201-11585)$ & $\begin{array}{c}590 \\
(288-7556)\end{array}$ & $\begin{array}{c}817 \\
(134-12341) \\
\end{array}$ & 310 (93 to 1269) & 0.02 & $500 \S$ & $400 \S$ \\
\hline Carotene $(\mu \mathrm{g})$ & $\begin{array}{c}783 \\
(219-3638)\end{array}$ & $\begin{array}{c}2510 \\
(523-11313)\end{array}$ & $2048(550-4657)$ & 3079 (956-6188) & $\begin{array}{c}1443 \\
(219-4657)\end{array}$ & $\begin{array}{c}2798 \\
(523-11313)\end{array}$ & 1376 (549 to 2452) & 0.004 & - & - \\
\hline Vitamin C (mg) & $\begin{array}{c}41.0 \\
(4.0-204)\end{array}$ & $\begin{array}{c}81.0 \\
(14.0-262)\end{array}$ & $40.0(3-165)$ & $61.0(27.0-291.0)$ & $40.5(3.0-204)$ & $80.5(14.0-219)$ & $33.5(2.0$ to 64.0$)$ & 0.03 & $25 \S$ & $25 \S$ \\
\hline Vitamin E (mg) & $\begin{array}{c}4.8 \\
(3.4-18.0)\end{array}$ & $\begin{array}{c}10.26 \\
(2.23-32.0)\end{array}$ & $4.5(2.3-6.0)$ & $5.38(3.6-14.7)$ & $4.7(2.3-18.0)$ & $7.8(2.2-32.0)$ & $2.9(1.45$ to 5.35$)$ & 0.0002 & $7 \dagger$ & $5 \dagger$ \\
\hline
\end{tabular}

*Based on values in kilocalories (men 2250, women 1940). †Age 19-49 years. $\ddagger$ Adults. $\S$ Age $\geqslant 15$. 
only 12 fruit and vegetable portions a week; the recommended intake is five portions a day. ${ }^{5}$

There was an association in female patients between mental state and alcohol intake. This association may have arisen by chance as, in all, 36 correlations were calculated. Also, association does not imply causality. Does a high alcohol intake worsen the mental state? Or does a disturbed mental state lead women to drink more?

We conclude that the schizophrenic patients we studied are making poor dietary choices. Assertive programmes to improve diet are necessary.

We thank the patients and staff of the Dumfries and Galloway Mental Health Association and the control subjects for their cooperation; Joan Brown, area dietician, for advice on dietary assessment and provision of training; Heather Barrington for statistical advice; and Mary Muirhead for secretarial help.

Contributors: RMcC initiated and coordinated the study, discussed core ideas, designed the protocol, participated in data analysis, and wrote the paper. JP initiated and coordinated the study, discussed core ideas, designed the protocol, participated in data analysis, and edited the paper. EM discussed core ideas, participated in clinical data collection and data analysis, and contributed to the paper. DT-S and JH discussed core ideas, participated in clinical data collection, and contributed to the paper $\mathrm{CB}$ and DW discussed core ideas, analysed blood samples, and contributed to the paper. RMcC and JP are guarantors for the study.

Funding: None

Conflict of interest: None

1 The Scottish diet. Edinburgh: Scottish Office Home and Health Department, 1993. (Report of a working party to the chief medical officer for Scotland.)

2 Yarnell JWG, Fehily AM, Milbank JF, Sweetnam PM, Walker CL. A short dietary questionnaire for use in an epidemiological survey: comparison with weighed dietary records. Human Nutrition:Applied Nutrition 1983:37A:103-12.

3 Catignani GL, Bieri JG. Simultaneous determination of retinol and a-tocopherol in serum or plasma by liquid chromatography. Clin Chem $1983 ; 29: 708-12$

Department of Health. Dietary reference values for food energy and nutrients in the United Kingdom. London: HMSO, 1991.

5 Heimendinger J, van Duvn MAS. Dietary behaviour change: the challenge of recasting the role of fruit and vegetables and the American diet. Am J Clin Nutr 1995;61:1397-401S.

(Accepted 26 June 1998)

\title{
Effect of fundholding on removing patients from general practitioners' lists: retrospective study
}

\author{
Dermot O’Reilly, Keith Steele, Barry Merriman, Andrew Gilliland, Scott Brown
}

Fundholding by general practitioners was introduced during NHS reforms in 1989. Little is known about its impact on the quality of patient care. ${ }^{1}$ One measure of this impact is the rate at which practices decide they do not wish to continue to provide general medical services for patients and remove them from their lists ("removal at general practitioner's request"). In Northern Ireland the rate of the removing patients from practitioners' lists increased after the introduction of fundholding in $1993^{2}$ which suggests that there is a relation between fundholding and removing patients from lists. We report an investigation to determine if becoming a fundholding practice changed the rates of removing patients from practice lists.

\section{Methods and results}

For the past 15 years the Central Services Agency has maintained a register of all patients removed from lists at a general practitioner's request. The database does not contain patients who have been removed for reasons such as leaving the country or moving outside the practice area. However, records are retained if the patient has died or emigrated. Demographic data were obtained for each patient removed from a list during the study, and each record was coded according to the fundholding status of the practitioner.

There were four waves of fundholding between 1987 and 1996; the first began in April 1993 and each new wave followed in April of the succeeding year. The data were divided into three phases for each fundholding practice: fundholding, preparatory year (the financial year prior to fundholding), and prepreparatory period (from January 1987 until the start of the preparatory year). The removal of an individual patient or family unit was counted as one decision, and only first time removals within the 10 year period were analysed. Rates for first removal decisions per 10000 person years were calculated for each period as previously described. ${ }^{2}$ Rates for non-fundholding practices were also examined using the commencement date of each wave of fundholding to artificially divide the data into before and after periods. In April 1996 there were 419 general practitioners in 114 practices serving 724104 patients.

Results of the analysis are shown in the table.There was no increase in the rate of removing patients from non-fundholding practices. Among fundholding practices the rate of removing patients increased from $1.8 / 10000$ person years in the prepreparatory period to $2.2 / 10000$ person years during the fundholding period; this was an increase of $21.4 \%$ (95\% confidence interval $7.4 \%$ to $35.5 \%$ ) Practices that became fundholding practices in later years removed patients more frequently and started removing patients at higher rates during the preparatory year.

\section{Comment}

The rates of removing patients from general practitioners' lists are influenced by characteristics of both the practice and population. ${ }^{2}$ In this analysis practices were compared with their earlier performance obviating these potentially confounding variables. The increases in the rates among fundholders are therefore intrinsically related to fundholding status. The different rates of removal occurring between successive waves of fundholders and between fundholders and nonfundholders could be attributed to differences in socio-
Health and Social Care Research Unit, Queen's University of Belfast, BT12 6BJ Dermot O'Reilly, deputy director Barry Merriman, research assistant

Department of General Practice, Queen's University of Belfast

Keith Steele, Andrew Gilliland, senior lecturer

Royal College of General Physicians Research Practice, Mountsandel Surgery, Coleraine BT52 1JB

Scott Brown, general practitioner Correspondence to: Dr O'Reilly d.oreilly@qub.ac.uk

BMJ 1998;317:785-6 